\title{
Cataract extraction after deep sclerectomy and its effect on intraocular pressure control
}

\author{
Karl Mercieca ${ }^{1} \cdot$ Divya Perumal $^{1} \cdot$ Kieren Darcy $^{2} \cdot$ Nitin Anand $^{3,4}$
}

Received: 13 December 2017 / Revised: 4 July 2018 / Accepted: 30 July 2018 / Published online: 31 October 2018

(c) The Royal College of Ophthalmologists 2018

\begin{abstract}
Purpose To estimate the incidence and predisposing factors for cataract extraction (CE) after Deep Sclerectomy (DS) with Mitomycin-C (MMC) and its effect on intraocular pressure (IOP) control.

Methods: Retrospective study of phakic eyes which had DS with MMC performed over a 5-year period. 179 eyes of 179 patients were included.

Results Mean age at time of DS was 68.6 \pm 9.7 years and mean follow-up was $89.4 \pm 29.4$ months. 63 eyes had CE and the probability of CE following DS was $0 \%$ at $1,11.6 \%$ at $3,21.0 \%$ at 5 and $33.2 \%$ at 7 years, with a $50 \%$ probability (median survival time) of 10 years. Age was association with increased risk for CE (Hazard ratio 1.05, 95\% CI: 1.03-1.08, $p<0.0001)$. Mean IOP had increased from $11 \mathrm{mmHg}$ to $15 \mathrm{mmHg}$ in the first 3 months and remained higher up to a year $(p<0.001)$. There was no difference in the probability of maintaining an IOP $<16 \mathrm{mmHg}$ without additional medications or needle revision ( $p=0.05$,Log-rank test). 20/47 eyes that failed were from the CE group, of which 14 (22.2\%) failed prior to CE. Number of eyes on glaucoma medications before CE was 6 (mean edications $0.2 \pm 0.5 \mathrm{~m}$ ) and by last follow-up, 9 eyes were on medications (mean medications $0.2 \pm 0.7$ ). Post-CE needle revision was performed on 4 eyes.

Conclusions The probability of CE after DS is low, with a gradual increase with time. Increasing age was found to be a statistically significant risk factor. There was a modest increase in IOP after CE and increase use of glaucoma medications.
\end{abstract}

\section{Introduction}

Cataract is commonly observed following trabeculectomy. The incidence of cataract extraction (CE) is between $20-52 \%$ at two to 7 years after trabeculectomy [1-6] and is higher than in age-matched controls on glaucoma medications [7, 8]. CE following trabeculectomy confers greater risks [2], and is associated with increased risk of bleb failure [1, 9-13].

In Deep Sclerectomy (DS), a thin outer scleral flap is maintained and loosely sutured to allow subconjunctival space filtration with bleb formation [14]. A permeable filtration membrane (the trabeculo-Descemet's membrane

Nitin Anand

anand1604@gmail.com

Manchester University Hospitals NHS Trust, Manchester, UK

2 University Hospital Bristol NHS Trust, Bristol, UK

3 Gloucestershire Hospitals NHS Foundation Trust, Cheltenham, UK

4 Calderdale and Huddersfield NHS Trust, Huddersfield, UK
(TDM)) is created, which provides aqueous-outflow resistance and reduces post-operative change in the anterior chamber. Iridectomy is not performed and YAG laser goniopuncture (LGP) and needling are performed to manage delayed intraocular pressure (IOP) rise $[15,16]$. Mitomycin-C (MMC) is used to enhance bleb formation and achieve low target intraocular pressure (IOP) [17]. A meta-analysis concluded that the absolute risk of surgically induced cataract is lower in non-penetrating glaucoma surgery (NPGS) compared to trabeculectomy [18], and that cataract progression occurs in $1-25 \%$ of eyes up to 5 years following DS [19-21]. However, none of these studies report actuarial probability of CE after DS.

In this study, we investigate the long-term actuarial probability and predisposing factors for CE following DS with MMC and the effect of CE on IOP control.

\section{Methods}

This is a retrospective, non-randomised, case-note review of all patients who underwent DS, performed or 
supervised by a single glaucoma consultant surgeon (NA) over a 5-year period, (August 2001 to August 2006) in Calderdale and Huddersfield NHS Trust. All patients were identified from a correlational ongoing database (Microsoft Access) which found that 345 eyes underwent phakic DS for primary open angle, pigmentary and pseudoexfoliative glaucoma. We excluded 27 eyes with intraoperative perforation as this effectively converts the operation into a trabeculectomy, 10 eyes with previous glaucoma surgery due to the known effect on cataract formation and 28 eyes which had no MMC application during DS. 277 eyes with primary MMC augmented DS were therefore identified. From these, further exclusions were made based on age $<40$ years ( 8 eyes), repeat glaucoma surgery before CE ( 21 eyes), follow-up $<1$ year (12 eyes) and second eye in bilateral cases (57 eyes). 179 eyes of 179 patients were thus included for final analysis. Patients with pre-existing cataracts were not excluded, however, although only one had visually significant cataract at baseline.

Data collected included demographics, Snellen BCVA, IOP, bleb characteristics, post-operative complications, interventions and medications. A standardised operative technique and postoperative management was used, which have been described previously [15-17]. The decision to perform CE was based on vision and impact on quality of life (glare, other subjective symptoms). There was a minimum of 6 months between CE and DS to reduce the potential risk of bleb failure. Phacoemulsification was done avoiding the DS site. Postoperatively, a topical steroid-antibiotic combination was prescribed for 8-12 weeks, depending on follow-up intervals and the degree of postoperative inflammation and bleb vascularity. Failure of DS was defined as an increase in number of glaucoma medications, bleb needling, or further glaucoma surgery to maintain IOP control [9, 22]. LGP or iridoplasty were not considered as failure. All needling procedures were done in the theatre. Due to the non-penetrating nature of DS, needlings included both subconjunctival (Type-1) and sub-flap (Type-2) scar dissection.

Medcalc $^{\circledast}$ (8400 Ostend, Belgium) was used for statistical analyses. Kaplan-Meier survival outcomes were calculated to establish the probability of CE after DS and IOP-control after CE. Cox's-regression-analysis was done to investigate survival curves; repeated-measuresANOVA to investigate IOP changes after CE; KruskalWallis and Wilcoxon tests to determine VA change; MannWhitney-U-test to determine the change in the number of glaucoma medication; and Chi-squared-test with Yatescorrection and Fisher's exact test were used for categorical data. $P$ values of $<0.05$ were considered statistically significant.
Table 1 Baseline demographics and operative variables. Mean followup after DS was $89.4 \pm 29.4$ months. Patients who had CE after DS were older and that $\mathrm{CE}$ was performed in 6 eyes with hypotony i.e. $\mathrm{IOP} \leq 5 \mathrm{mmHg}$

\begin{tabular}{lllll}
\hline & All & Phakic & Cataract & $p$ value \\
\hline Number & 179 & 116 & 63 & \\
Age at time of & $68.6 \pm$ & $67.08 \pm$ & $71.2 \pm 7.4$ & $<0.001$ \\
$\begin{array}{l}\text { DS (years) } \\
\text { Follow-up after }\end{array}$ & 9.7 & 10.5 & & \\
DS in months & $89.4 \pm$ & $81.8 \pm$ & $97.7 \pm 30.4$ & $<0.001$ \\
Race & 29.4 & 25.3 & & \\
$\quad$ & & & & \\
$\quad$ Caucasian & 173 & 114 & 59 & \\
$\quad$ African & 5 & 2 & 3 & \\
$\quad$ Indian & 1 & 0 & 1 & \\
Sex (Male/Female) & $97 / 82$ & $60 / 56$ & $37 / 26$ & 0.9 \\
$\begin{array}{l}\text { Number of eyes on } \\
\text { glaucoma medications }\end{array}$ & 6 & 0 & 6 & \\
\hline
\end{tabular}

\section{Results}

Baseline characteristics are shown in Table 1. DS complications and post-operative procedures are shown in Table 2. Eyes which had undergone LGP were more likely to eventually have $\mathrm{CE}$ (p-0.004). 35 eyes had IOP $<10 \mathrm{~mm} \mathrm{Hg}$ following DS, of which 17 eyes had CE $(p=0.09)$. No patient had CE in the first year after DS. In the second year, 12 patients $(6.7 \%)$ had CE with subsequent probabilities of $\mathrm{CE}$ was $0 \%$ at $1,11.6 \%$ at $3,21.0 \%$ at 5 and $33.2 \%$ at 7 years with a median survival time of 10 years (Fig. 1a). Cox's-regressionanalyses showed a significant influence of age (Hazard ratio $1.05,95 \% \mathrm{CI}: 1.03-1.08, p<0.0001)$ on the probability of CE (Table 3).

There was no significant difference between groups in the probability of maintaining an IOP $<16 \mathrm{mmHg}$ after DS without additional medications or needle revision $(\mathrm{p}=0.05$, Log-rank test). During the follow-up, 47 eyes failed by the aforementioned criteria, of which 20 were from the CE group. Only six eyes $(9.5 \%)$ post- and 14 eyes $(22.2 \%)$ preCE were deemed to have failed (Fig. 1b).

Complications and procedures with $\mathrm{CE}$ are shown in Table 4. Out of the 63 eyes that had CE, 5 were excluded from further analyses. One each had a follow-up of less than 3 months post-CE, concurrent repair of leaking revision of failed DS, concurrent penetrating keratoplasty and required revision at the time of CE. Mean followup after CE was $43.6 \pm 26.3$ months. 45 eyes completed 1-year (77.6\%), 43 eyes completed more than 2-years (74.1\%) and 23 eyes had completed more than 3-years of follow-up (39.7\%). The probability of failure was $15.8 \%$ at 2 -years and $18.2 \%$ at 4 -years (Fig. 1c). There was no significant association with age, LGP, MMC-use, 
Table 2 Complications and procedures after deep sclerectomy but before cataract surgery. $*$ delayed hypotony refers to IOP $\leq 5 \mathrm{mmHg}$ for greater than 6 months or associated with macular folds)

\begin{tabular}{|c|c|c|c|c|}
\hline & All & Phakic & Cataract & $p$ value \\
\hline Total & 179 & 116 & 63 & \\
\hline \multicolumn{5}{|l|}{ Complications after deep sclerectomy } \\
\hline $\begin{array}{l}\text { Shallow anterior chamber at } \\
\text { week } 1\end{array}$ & 3 & 2 & 1 & \\
\hline Conjunctival edge leak & 12 & 8 & 4 & \\
\hline $\begin{array}{l}\text { Acute IOP rise }>30 \mathrm{mmHg} \text { due } \\
\text { to iris occlusion of LGP }\end{array}$ & 8 & 5 & 3 & \\
\hline Delayed bleb leak & 2 & 1 & 1 & \\
\hline Blebitis & 1 & 1 & 1 & \\
\hline $\begin{array}{l}\text { Descemet's Membrane } \\
\text { Detachment }\end{array}$ & 1 & 0 & 1 & \\
\hline $\begin{array}{l}\text { Bleb dysesthesia requiring bleb } \\
\text { excision }\end{array}$ & 1 & 1 & 0 & \\
\hline Delayed Hypotony* & 10 & 6 & 4 & \\
\hline Iris synechiae at TDM & 70 & 35 & 25 & \\
\hline \multicolumn{5}{|l|}{ Procedures after deep sclerectomy } \\
\hline Nd:YAG Laser Goniopuncture & 132 & 79 & 53 & 0.004 \\
\hline $\begin{array}{l}\text { Needle Revision with } \\
\text { antimetabolite injection }\end{array}$ & 52 & 16 & 15 & 0.06 \\
\hline $\begin{array}{l}\text { Nd:YAG and/or Argon Laser } \\
\text { Iridoplasty }\end{array}$ & 62 & 35 & 27 & 0.12 \\
\hline \multicolumn{5}{|c|}{$\begin{array}{l}\text { Causes for more than } 2 \text { lines Snellen Visual Acuity Loss from pre- } \\
\text { Deep Sclerectomy to last follow-up }\end{array}$} \\
\hline $\begin{array}{l}\text { Age- related macular } \\
\text { degeneration }\end{array}$ & 4 & 2 & 2 & \\
\hline Glaucoma progression & 4 & 2 & 2 & \\
\hline Cataract progression & 1 & 1 & 0 & \\
\hline Vitreo-macular traction & 1 & 1 & 0 & \\
\hline Ocular surface/ Corneal disease & 2 & 0 & 2 & \\
\hline Unknown & 3 & 1 & 2 & \\
\hline
\end{tabular}

Abbreviation: TDM Trabecular-Descemet Membrane

pre-CE needle revision and pre-CE IOP of $<11 \mathrm{~mm} \mathrm{Hg}$ (Cox's regression model; $p>0.05$ ).

The mean IOP before $\mathrm{CE}$ was $11.4 \pm 4.4 \mathrm{mmHg}$ and increased significantly $(p<0.001)$ up to a year after CE (Fig. 1d). Repeated-measures ANOVA models show no significant difference for changes in IOP after CE up to 2, 3 and 4 years. Number of eyes on glaucoma medications before CE was 6 (mean number of medications $0.2 \pm 0.5$ ) and by last follow-up it was 9 eyes (mean number of medications $0.2 \pm 0.7 ; p=0.5$ ). Post-CE needle revision was performed in 4 eyes $(6.9 \%)$ and was successful in lowering IOP by $>30 \%$ in all eyes until last follow-up. VA trends are represented in Fig. 1e, f.

A total of 13 eyes (7 from phakic and 6 from CE group) lost $\geq 2$ Snellen VA lines during follow-up. The causes for reduced vision are shown in Table 2.

\section{Discussion}

Previous studies investigating the prevalence of CE following NPGS were limited by small numbers, short followups, and no Kaplan-Meier survival probabilities. Lachkar et al. noted that 17 of 179 patients underwent CE following DS with a mean follow-up of 54 months [19]. Shaarawy et al. noted cataract progression in a quarter of patients' with 64 months mean follow-up [21]. Our study's mean follow-up of over 7 years found that CE probability following DS was quite low, with no cases requiring $\mathrm{CE}$ in the first year and only a gradual increase over time. Older age at time of DS was positively correlated with risk for CE.

The incidence of CE varied from $21.5 \%$ at 7.5 years after trabeculectomy in the CIGTS (mean age 58years) to almost $50 \%$ at 5 years in the AGIS [2]. We showed that the probability of CE following DS was $33.2 \%$ at 7 years. Trabeculectomy is more likely to cause cataract than medical or laser therapy for glaucoma [23, 24]. We postulate that a surgical iridectomy may decrease aqueous flow across the lens and disrupt mechanisms that preserve transparency. Additionally, post-operative inflammation and hypotony may increase the risk of cataract [2]. Chiou et al. found less post-operative inflammation in DS [25], while Rulli et al. showed less post-operative complications in NPGS [18]. The anterior chamber and aqueous dynamics are more stable in NPGS and our study did not find an association between hypotony and cataract formation following DS.

The use of MMC may be associated with an increased risk of cataract in trabeculectomy (due to potential toxicity to lens epithelium [26]) and delayed hypotony [17]. Our study found no statistical significant association between MMC use and CE. However, a weaker association was observed in patients requiring MMC needle revision (relative risk 1.37, $p=0.39$ ), which may be due to potential exposure to subconjunctival MMC. Our results also show an association between LGP and cataract development.

Age is associated with cataract formation following trabeculectomy. In AGIS, the mean age for patients undergoing CE was 65 compared to 55 years for those who did not. The cataract risk in AGIS increased by $7 \%$ for a 1-year increase in age [2, 23]. A UK-audit reported that 111 of 376 phakic eyes required CE following trabeculectomy [27]. The mean age of this cohort was 69.5 years with mean follow-up of 40 months. In comparison, the mean patient age of 71.2 years in our study (with mean follow-up of 89 months) appears to show that age-adjusted risk of CE after DS may be lower compared to that of uncomplicated trabeculectomy.

A Spanish prospective study on IOP changes after phacoemulsification post-trabeculectomy reported a mean IOP increase from 12 to $16 \mathrm{mmHg}$ for the first 3 months after CE [9]. The mean IOP then remained between 14 and $15 \mathrm{~mm}$ 
A

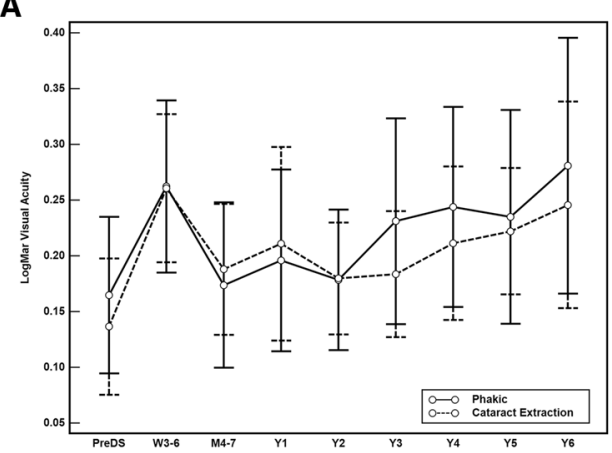

C

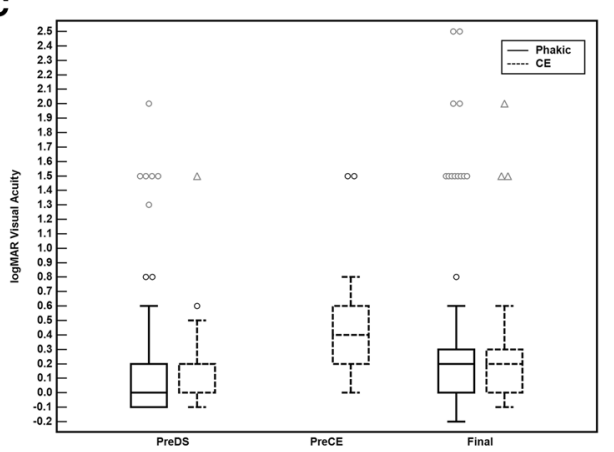

E

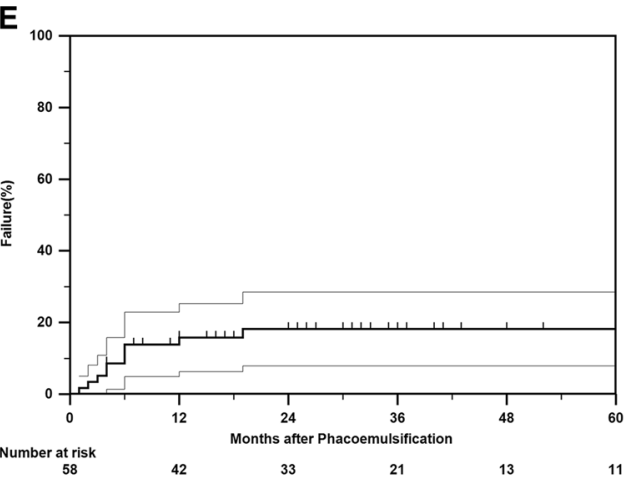

B

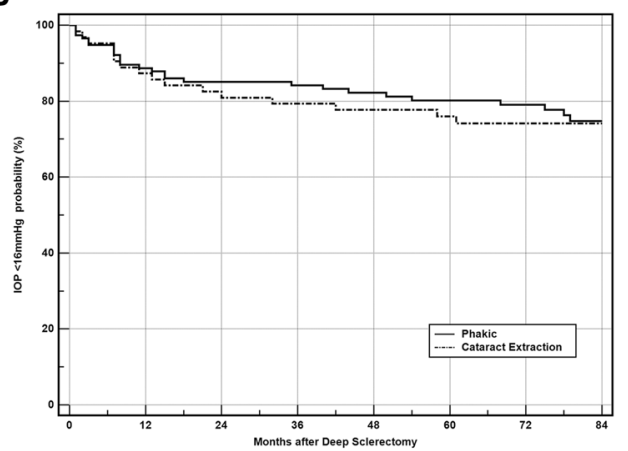

D

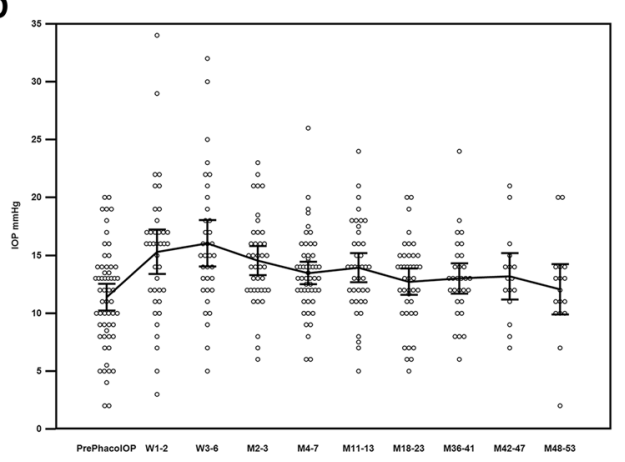

$\mathbf{F}$

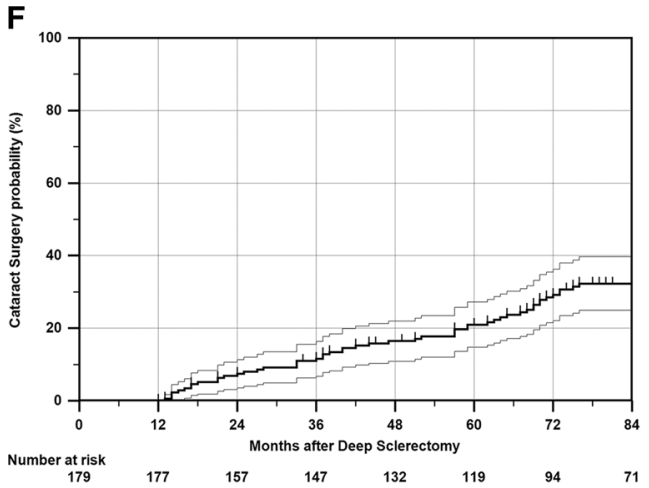

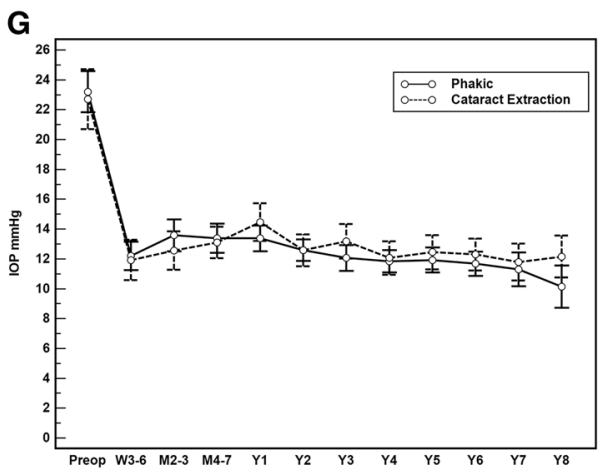

$\mathrm{Hg}$ for the following 2 years with $65.3 \%$ of patients not needing IOP-lowering medication during this period. Failure rates (defined as addition of medication, needle revision or further surgery) was $44 \%$ at 2 years. A reduction in bleb size was also noted in $77.6 \%$ of these eyes by the last postoperative visit. Two other retrospective studies on CE after 
Fig. 1 a Kaplan-Meier graph showing the probability of cataract extraction after Deep Sclerectomy (95\% confidence intervals) b. Kaplan-Meier graph showing probability of maintaining an IOP $<16$ $\mathrm{mmHg}$ without additional medication or needle revision. c KaplanMeier probability of failure after phacoemulsification in eyes with previous deep sclerectomy (95\% confidence intervals). $\mathbf{d}$ The effect of phacoemulsification on DS. Graph showing the change in intraocular pressure following phacoemulsification. Error bars are $95 \%$ confidence intervals. e Box-whisker plots showing the change in visual acuity in eyes after phacoemulsification (CE) and phakic eyes post-deep sclerectomy. Snellen Visual Acuity was converted to LogMAR Visual Acuity. Error bars are 95\% confidence intervals of mean LogMAR VA. preDS $=$ VA prior to deep sclerectomy, preCE $=\mathrm{VA}$ prior to phacoemulsification, Final $=$ VA at last visit. The central box represents the values from the lower to upper quartile (25-75 percentile). The middle line represents the median. In the CE group, mean VA decreased from 0.14 to 0.43 prior to phacoemulsification and the improved to 0.26 by last follow-up $(p=0.001)$. In eyes which did not have CE, mean VA decreased from 0.26 to 0.33 by last follow-up ( $p<$ 0.001). f Visual acuity comparison between patients who remained phakic vs. those who underwent cataract surgery following deep sclerectomy with time (Mean with 95\% Confidence Intervals). There was no significant difference in logMAR VA between the two groups at all measured intervals $(p>0.5)$. $\mathrm{g}$ Intraocular pressure change in patients who remained phakic vs. those who underwent cataract surgery following deep sclerectomy with time (Mean with 95\% Confidence Intervals). PreDS IOP prior to DS, M month, Y year, W week

Table 3 Results of Cox's Regression Analyses for possible risk factors for cataract surgery after deep sclerectomy

\begin{tabular}{|c|c|c|c|}
\hline & $\begin{array}{l}\text { Hazard } \\
\text { Ratio }\end{array}$ & $\begin{array}{l}95 \% \text { confidence } \\
\text { intervals }\end{array}$ & $p$ value \\
\hline Age & 1.05 & 1.03 to 1.08 & $<0.0001$ \\
\hline Female & 0.79 & 0.46 to 1.34 & 0.39 \\
\hline $\begin{array}{l}\text { Needle revision with } \\
\text { Mitomycin-C }\end{array}$ & 1.37 & 0.71 to 2.62 & 0.39 \\
\hline $\begin{array}{l}\text { Postoperative argon/Nd: } \\
\text { YAG laser iridoplasty }\end{array}$ & 1.30 & 0.75 to 2.26 & 0.34 \\
\hline $\begin{array}{l}\text { Postoperative IOP }<10 \\
\mathrm{mmHg} \text { (beyond } 6 \text { months) }\end{array}$ & 1.00 & 0.57 to 1.76 & 0.99 \\
\hline
\end{tabular}

Abbreviation: TDM trabecular-Descemet Membrane

trabeculectomy with similar failure criteria and follow-up reported failure rates of $23-26 \%[22,28]$.

The IOP changes in our study were remarkably similar to Rebolleda et al. [9]. There was an initial increase in mean IOP by $3-4 \mathrm{mmHg}$, followed by a decline of $2 \mathrm{mmHg}$ after 6 weeks. This decline could partially attributed to the addition of glaucoma medication, needling procedures or reduced post-operative inflammation. At last followup, $95 \%$ of patients were not on glaucoma medications and the failure rate following $\mathrm{CE}$ was $15.8 \%$ at 2 years and $18.2 \%$ at 4 years. Hence, it would appear that IOP changes after CE in DS are broadly similar to those expected in trabeculectomy.

The current study has several limitations. It is retrospective, lacks a control group, and there is no
Table 4 Complications during/after phacoemulsification in eyes with prior deep sclerectomy and subsequent procedures performed

\begin{tabular}{|c|c|}
\hline & Number $(\%)$ \\
\hline \multicolumn{2}{|l|}{ Complications observed during phacoemulsification } \\
\hline Posterior capsule rupture & 2 \\
\hline \multicolumn{2}{|l|}{ Complications observed after phacoemulsification } \\
\hline Postoperative IOP increase $>10 \mathrm{mmHg}$ & 5 \\
\hline Endophthalmitis & 1 \\
\hline Blebitis & 1 \\
\hline Delayed Bleb Leaks & 2 \\
\hline Subluxated IOL & 1 \\
\hline Iris incarceration in perforation/goniopuncture site & 2 \\
\hline Hypotony after Needle Revision & 1 \\
\hline Total number of eyes with complications & 14 \\
\hline \multicolumn{2}{|l|}{ Procedures after phacoemulsification } \\
\hline Needle revision—-total & 7 \\
\hline 5-Fluorouracil & 5 \\
\hline Topical Mitomycin-C & 1 \\
\hline Subconjunctival Mitomycin-C & 1 \\
\hline Anterior Chamber Paracentesis & 4 \\
\hline Revision of DS with subconjunctival Bevacizumab & 1 \\
\hline Trabeculectomy with MMC & 1 \\
\hline Intravitreal Antibiotics & 2 \\
\hline Intravitreal Bevacizumab & 1 \\
\hline $\begin{array}{l}\text { Anterior vitrectomy \& surgical removal of iris from } \\
\text { perforation of TDM }\end{array}$ & 1 \\
\hline Ectropion surgery & 1 \\
\hline Subconjunctival autologous blood & 2 \\
\hline Nd:YAG laser goniopuncture & 11 \\
\hline Argon \& Nd:YAG Laser Iridoplasty & 5 \\
\hline Selective Laser Trabeculoplasty & 3 \\
\hline Nd:YAG Laser Capsulotomy & 2 \\
\hline Nd:YAG Laser Iridotomy & 1 \\
\hline Argon Laser Panretinal Photocoagulation & 1 \\
\hline Total number of eyes with procedures & 29 \\
\hline
\end{tabular}

differentiation between age-related and surgically induced cataract progression. Comparison with cataract progression after trabeculectomy is difficult due to differing criteria for cataract progression. For example, in AGIS [2], cataract progression was defined as having $\mathrm{CE}$ or confirmed severe lens opacity with a ETDRS BCVA score $<65$ letters. The indication for CE, in this study, is based on patientreported decrease in vision and may underestimate the 'true' probability of cataract progression. Information was not collated on potential systemic disorders (such as diabetes) which may have increased the risk of cataract formation. Furthermore, these results cannot be extrapolated to other types of NPGS, where LGP and needle revision are not routinely performed. 
In summary, this is the largest study in current literature describing the incidence of $\mathrm{CE}$ following $\mathrm{DS}$ and its effect on IOP. The probability of CE increases with duration following DS. Age-adjusted risk of $\mathrm{CE}$ after DS may be lower compared to that of uncomplicated trabeculectomy. Post-operative manipulations may convert DS to a fistulising procedure and possible exposure to MMC may increase the incidence of CE. CE has an adverse effect on IOP, which is similar to other bleb forming procedures.

\section{Summary}

\section{What was known before:}

- Previous studies investigating the prevalence of cataract and cataract surgery following non-penetrating glaucoma surgery were limited by small numbers, short follow-ups, and no Kaplan-Meier probabilities for cataract extraction.

- There is limited data on the effect of cataract surgery on intraocular pressure in eyes which had previously undergone deep sclerectomy.

\section{What this study adds:}

- This is the largest study describing the incidence of cataract surgery following deep sclerectomy (DS) and its effect on intraocular pressure.

- We had a mean follow-up period of 7 years.

- This study has shown that the probability of cataract surgery is low at $0 \%$ in the first year and gradually increasing with time, with a $50 \%$ chance of requiring cataract extraction at 10 years following DS.

- Factors which may contribute to this lower risk are discussed. The risk of developing cataracts was higher in older patients.

- Cataract surgery was associated with an increased intraocular pressure and need for increased number of glaucoma medications.

- These are factors which need to be discussed with patients prior to undergoing cataract surgery and are important in the post-operative management of patients who have undergone this surgery.

\section{Compliance with ethical standards}

Conflict of interest The authors declare that they have no conflict of interest.

\section{References}

1. Anderson DR, Drance SM, Schulzer M. Factors that predict the benefit of lowering intraocular pressure in normal tension glaucoma. Am J Ophthalmol. 2003;136:820-9.

2. AAGIS (Advanced Glaucoma Intervention Study) Investigators. The Advanced Glaucoma Intervention Study: 8. Risk of cataract formation after trabeculectomy. Arch Ophthalmol. 2001;119: 1771-9.

3. Musch DC, Gillespie BW, Niziol LM, Janz NK, Wren PA, Rockwood EJ, et al. Cataract extraction in the collaborative initial glaucoma treatment study: incidence, risk factors, and the effect of cataract progression and extraction on clinical and quality-oflife outcomes. Arch Ophthalmol. 2006;124:1694-700.

4. Tornqvist G, Drolsum LK. Trabeculectomies. A long-term study. Acta Ophthalmol (Copenh). 1991;69:450-4.

5. Wong TT, Khaw PT, Aung T, Foster PJ, Htoon HM, Oen FT, et al. The singapore 5-Fluorouracil trabeculectomy study: effects on intraocular pressure control and disease progression at 3 years. Ophthalmology. 2009;116:175-84.

6. Palanca-Capistrano AM, Hall J, Cantor LB, Morgan L, Hoop J, WuDunn D. Long-term outcomes of intraoperative 5-fluorouracil versus intraoperative mitomycin $\mathrm{C}$ in primary trabeculectomy surgery. Ophthalmology. 2009;116:185-90.

7. Herman DC, Gordon MO, Beiser JA, Chylack LT Jr., Lamping KA, Schein OD, et al. Topical ocular hypotensive medication and lens opacification: evidence from the ocular hypertension treatment study. Am J Ophthalmol. 2006;142:800-10.

8. Chandrasekaran S, Cumming RG, Rochtchina E, Mitchell P. Associations between elevated intraocular pressure and glaucoma, use of glaucoma medications, and 5-year incident cataract: the Blue Mountains Eye Study. Ophthalmology. 2006;113:417-24.

9. Rebolleda G, Munoz-Negrete FJ. Phacoemulsification in eyes with functioning filtering blebs: a prospective study. Ophthalmology. 2002;109:2248-55.

10. Awai-Kasaoka N, Inoue T, Takihara $\mathrm{Y}$, Kawaguchi A, Inatani M, Ogata-Iwao $\mathrm{M}$, et al. Impact of phacoemulsification on failure of trabeculectomy with mitomycin-C. J Cataract Refract Surg. 2012;38:419-24.

11. Ehrnrooth P, Lehto I, Puska P, Laatikainen L. Phacoemulsification in trabeculectomized eyes. Acta Ophthalmol Scand. 2005;83:561-6.

12. Swamynathan K, Capistrano AP, Cantor LB, WuDunn D. Effect of temporal corneal phacoemulsification on intraocular pressure in eyes with prior trabeculectomy with an antimetabolite. Ophthalmology. 2004;111:674-8.

13. Casson R, Rahman R, Salmon JF. Phacoemulsification with intraocular lens implantation after trabeculectomy. J Glaucoma. 2002;11:429-33.

14. Konstantopoulos A, Yadegarfar ME, Yadegarfar G, Stinghe A, Macleod A, Jacob A, et al. Deep sclerectomy versus trabeculectomy: a morphological study with anterior segment optical coherence tomography. Br J Ophthalmol. 2013;97:708-14.

15. Anand N, Pilling R. Nd:YAG laser goniopuncture after deep sclerectomy: outcomes. Acta Ophthalmol. 2010;88:110-5.

16. Koukkoulli A, Musa F, Anand N. Long-term outcomes of needle revision of failing deep sclerectomy blebs. Graefe's Arch Clin Exp ophthalmol. 2015;253:99-106.

17. Anand N, Kumar A, Gupta A. Primary phakic deep sclerectomy augmented with mitomycin C: long-term outcomes. J Glaucoma. 2011;20:21-7.

18. Rulli E, Biagioli E, Riva I, Gambirasio G, De Simone I, Floriani I, et al. Efficacy and safety of trabeculectomy vs nonpenetrating surgical procedures: a systematic review and meta-analysis. JAMA Ophthalmol. 2013;131:1573-82. 
19. Lachkar Y, Neverauskiene J, Jeanteur-Lunel MN, Gracies H, Berkani M, Ecoffet M, et al. Nonpenetrating deep sclerectomy: a 6-year retrospective study. Eur J Ophthalmol. 2004;14:26-36.

20. Rho S, Kang SY, Hong S, Seong GJ, Jung JJ, Kim CY. Long-term results of deep sclerectomy with small collagen implant in Korean. Korean J Ophthalmol: Kjo. 2013;27:34-8.

21. Shaarawy T, Mansouri K, Schnyder C, Ravinet E, Achache F, Mermoud A. Long-term results of deep sclerectomy with collagen implant. J Cataract Refract Surg. 2004;30:1225-31.

22. Chen PP, Weaver YK, Budenz DL, Feuer WJ, Parrish RK 2nd. Trabeculectomy function after cataract extraction. Ophthalmology. 1998;105:1928-35.

23. Comparison of glaucomatous progression between untreated patients with normal-tension glaucoma and patients with therapeutically reduced intraocular pressures. Collaborative NormalTension Glaucoma Study Group. Am J Ophthalmol. 1998;126: 487-97.
24. Zahid S, Musch DC, Niziol LM, Lichter PR. Risk of endophthalmitis and other long-term complications of trabeculectomy in the Collaborative Initial Glaucoma Treatment Study (CIGTS). Am J Ophthalmol. 2013;155:674-80. 80.e1

25. Chiou AG, Mermoud A, Jewelewicz DA. Post-operative inflammation following deep sclerectomy with collagen implant versus standard trabeculectomy. Graefe's Arch Clin Exp ophthalmol. 1998;236:593-6.

26. Wilkins $\mathrm{M}$, Indar $\mathrm{A}$, Wormald $\mathrm{R}$. Intra-operative mitomycin $\mathrm{C}$ for glaucoma surgery. Cochrane Database Syst Rev. 2001:Cd002897.

27. Kirwan JF, Lockwood AJ, Shah P, Macleod A, Broadway DC, King AJ, et al. Trabeculectomy in the 21st century: a multicenter analysis. Ophthalmology. 2013;120:2532-9.

28. Crichton AC, Kirker AW. Intraocular pressure and medication control after clear corneal phacoemulsification and AcrySof posterior chamber intraocular lens implantation in patients with filtering blebs. J Glaucoma. 2001;10:38-46. 